\title{
The northern auroral region as observed in nitric oxide
}

\author{
C.A. Barth, D.N. Baker, and K.D. Mankoff \\ Laboratory for Atmospheric and Space Physics, University of Colorado at Boulder
}

\author{
S.M. Bailey \\ Center for Atmospheric Sciences, Hampton University, Hampton, VA
}

\begin{abstract}
The distribution of thermospheric nitric oxide in the northern polar region has been measured from the Student Nitric Oxide Explorer (SNOE). A polar image of a one-year average at $106 \mathrm{~km}$ shows the maximum density lies between $60^{\circ}$ and $70^{\circ} \mathrm{N}$ geomagnetic latitude. The density around this auroral oval varies as a function of longitude with the larger densities occurring at western geomagnetic longitudes. A polar image of a second year of observations demonstrates the same latitudinal-longitudinal density distribution indicating that the asymmetry is a persistent property of the auroral region. For a period of high geomagnetic activity, the nitric oxide observations indicate that the flux of precipitating electrons at $90^{\circ} \mathrm{W}$ geomagnetic longitude was $75 \%$ larger than the flux at $90^{\circ} \mathrm{E}$ geomagnetic longitude. We suggest that this asymmetry is caused by the longitudinal variation in the magnetic field strength around the auroral oval.
\end{abstract}

\section{Introduction}

The concept of an auroral oval originated from the analysis of all-sky camera images of the visible aurora obtained during the International Geophysical Year (IGY) [e.g., $A k a-$ sofu, 1977; Feldstein and Galperin, 1985]. The auroral oval is the region where the maximum flux of precipitating electrons interacts with the atmosphere producing ionization, luminosity, and heating. This region is usually described using magnetic local time coordinates (MLT) with the earth and its geographic features rotating below the auroral oval. Satellite images of the ultraviolet aurora measure the entire oval instantaneously [e.g., Frank and Craven, 1988]. A sequence of these images shows the auroral oval fixed in space with continents rotating beneath the oval. A survey of over 17,000 images obtained with the Polar UVI instrument shows the most intense auroral emissions occurring near $2230 \mathrm{MLT}$ and $68^{\circ} \mathrm{N}$ geomagnetic latitude [Liou et al., 1997]. A large survey $\left(1.5 \times 10^{8}\right.$ events $)$ of electron precipitation data shows the maximum probability of observing an electron aurora occurs near a magnetic local time of 2100 and a geomagnetic latitude of $67^{\circ} \mathrm{N}$ [Newell et al., 1996].

Nitric oxide is produced in the auroral region by electrons precipitating into the atmosphere in the $1-10 \mathrm{keV}$ range. The maximum density of nitric oxide occurs in the 100-110 $\mathrm{km}$ altitude region where precipitating electrons produce the maximum rate of ionization. This paper presents two years

Copyright 2001 by the American Geophysical Union.

Paper number 2000GL012649.

0094-8276/01/2000GL012649\$05.00 of measurements of nitric oxide in the northern polar region. The density distribution of nitric oxide at $106 \mathrm{~km}$ is used to determine the flux of precipitating electrons that produce the observed nitric oxide. Since the time constants for the production and loss of nitric oxide are long ( 0.8 days), the nitric oxide density is a measure of the amount of electron precipitation that has taken place during the previous day.

\section{Observations}

Nitric oxide is measured in the auroral regions from the Student Nitric Oxide Explorer (SNOE) polar-orbiting satellite [Barth et al., 1999]. The nitric oxide density is determined from the fluorescence scattering of ultraviolet sunlight by nitric oxide, which is measured with an ultraviolet spectrometer (UVS). The satellite is in a nearly circular, sunsynchronous orbit at an altitude of $556 \mathrm{~km}$ with an orbital period of 96 minutes and an inclination of 97.75 degrees. Using the spinning motion of the satellite, the UVS telescope scans the limb five times per minute, producing altitude profiles of the nitric oxide density between 90 and $170 \mathrm{~km}$. The nitric oxide is measured on the daylight portion of the orbit at a local time of 10:30 AM.

Global images have been made of the distribution of nitric oxide in the northern auroral region for a variety of time periods and geophysical conditions. The global image shown in Figure 1 displays the average nitric oxide density at $106 \mathrm{~km}$ altitude for a one-year period starting at the spring equinox, March 20, 1998. Data from over a half a million individual limb observations are included in this image. The measurements are sorted into 18 latitude bins and 15 longitude bins.

Nitric oxide is produced in the thermosphere both by auroral particles and by the action of solar soft x-rays on the atmospheric gases. The nitric oxide produced by the solar $\mathrm{x}$-rays has its maximum in the tropics but extends poleward toward the auroral region particularly during the solstices. In Figure 1, the contribution of the nitric oxide from the solar x-rays has been removed from the nitric oxide measured by the SNOE UVS instrument. A photochemical model was used to calculate the amount of nitric oxide produced by the solar soft x-rays using the flux measured by the SNOE solar soft x-ray photometer [Bailey et al., 1999]. The calculated nitric oxide for this one-year period was summed and the average subtracted from the observed nitric oxide. The resulting image in Figure 1 shows the yearly average of nitric oxide that is attributed to auroral electron precipitation.

Figure 1 has the north geomagnetic pole $\left(81.5^{\circ} \mathrm{N}, 82.5^{\circ}\right.$ $\mathrm{W}$ geographic coordinates) in the center of the image. The grids drawn on this image are in corrected geomagnetic coor- 
Nitric Oxide Density $\left(10^{7} \mathrm{~cm}^{-3}\right)$

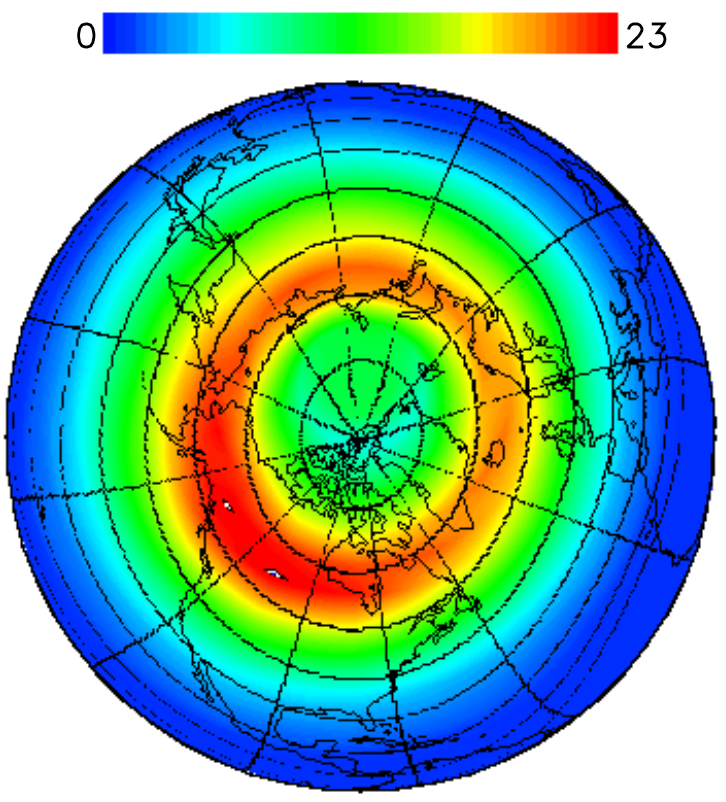

Figure 1. Polar image of nitric oxide density at an altitude of $106 \mathrm{~km}$ determined from one year of SNOE observations, March 20, 1998 - March 20, 1999. The largest nitric oxide density is located between $60^{\circ}-70^{\circ} \mathrm{N}$ geomagnetic latitude. The grid lines indicate geomagnetic latitude and longitude (CGM). The $0^{\circ}$ longitude line crosses the east coast of the United States near the bottom of the image.

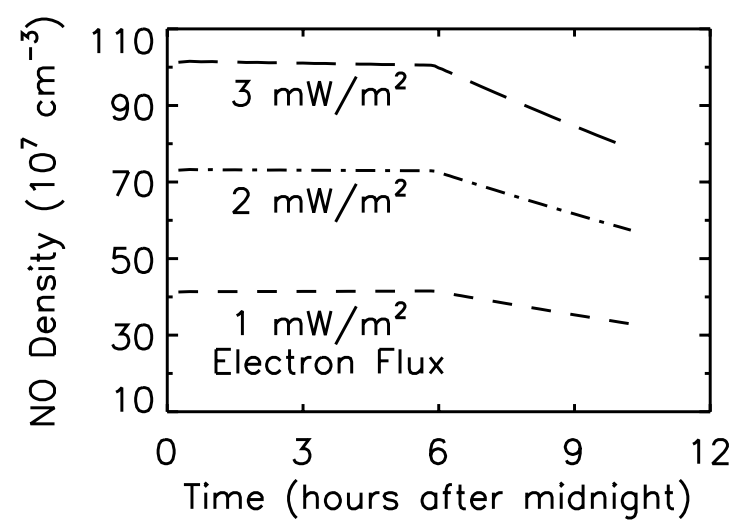

Figure 3. Calculations of the density of nitric oxide at 106 $\mathrm{km}$ at $65^{\circ} \mathrm{N}$ for the period from midnight until 10:30 AM in the morning when the SNOE measurements are made. In the time-dependent model calculation, electron fluxes of 1,2 , and 3 $\mathrm{mW} / \mathrm{m}^{2}$ were turned on at $6 \mathrm{PM}$ and then turned off at midnight. All three curves show the decrease in nitric oxide that occurs after dawn.

\section{Nitric Oxide Density $\left(10^{7} \mathrm{~cm}^{-3}\right)$}

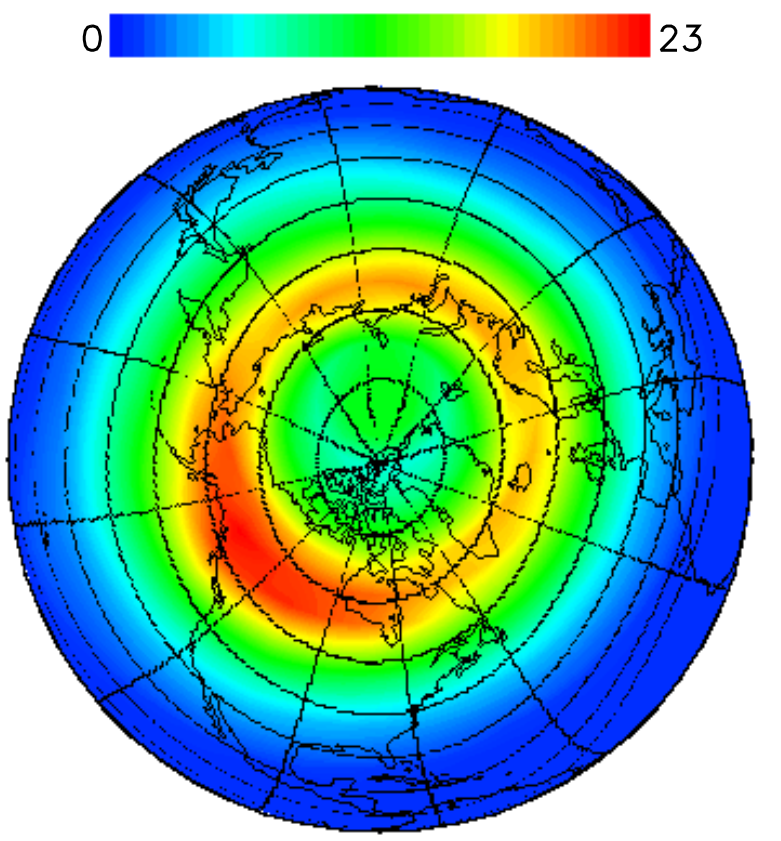

Figure 2. Polar image of nitric oxide density at an altitude of $106 \mathrm{~km}$ determined from one year of SNOE observations, March 20, 1999 - March 20, 2000. Both Figure 1 and 2 show the same asymmetric longitudinal distribution of nitric oxide.

\section{Nitric Oxide Density $\left(10^{7} \mathrm{~cm}^{-3}\right)$}

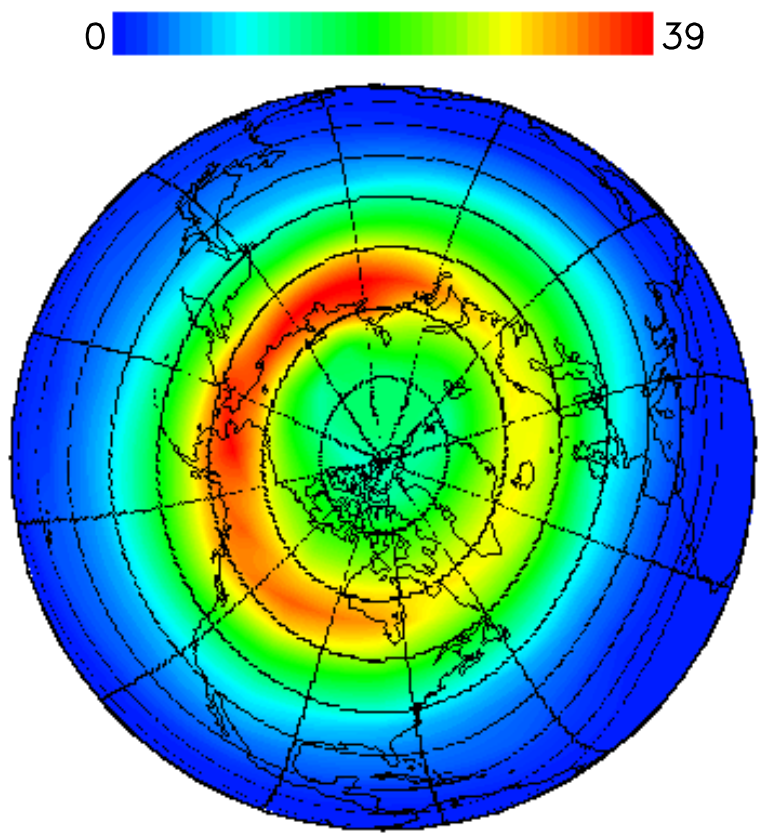

Figure 4. Polar image of the density of nitric oxide at 106 $\mathrm{km}$ for the equinox periods between March 20, 1998 and March 20, 1999. These observations were made on those days when the geomagnetic activity index Ap was greater than 12 . The grid lines are in geomagnetic coordinates (CGM). The $0^{\circ}$ longitude line crosses the east coast of the United States near the bottom of the image. The density of nitric oxide in the auroral oval is larger at longitude $90^{\circ} \mathrm{W}$ than at $90^{\circ} \mathrm{E}$. 
dinates (CGM). The maximum nitric oxide density lies approximately between $60^{\circ}$ and $70^{\circ} \mathrm{N}$ geomagnetic latitude. The distribution of nitric oxide has the appearance of an oval because of the shape of the lines of geomagnetic latitude on this orthographic projection. However, the nitric oxide density is not uniform around the auroral oval indicating that the flux of precipitating electrons is not uniform. The density and, hence, the electron flux is larger near a geomagnetic longitude of $90^{\circ} \mathrm{W}$ and smaller near a geomagnetic longitude of $90^{\circ} \mathrm{E}$. The low-latitude boundary of the region of high density extends equatorward of $60^{\circ} \mathrm{N}$ geomagnetic latitude near $90^{\circ} \mathrm{W}$ and lies poleward of $60^{\circ} \mathrm{N}$ near $60^{\circ} \mathrm{E}$.

Since the major contribution to the enhanced nitric oxide density during a one-year period is from dozens of geomagnetic storms, the question arises, "Is the spatial distribution of auroral nitric oxide observed in this one-year period (Spring 1998 to Spring 1999) typical or does the distribution vary randomly from year to year"? To explore this question, another one-year period starting March 20, 1999 was analyzed in the same way as the Year One data set. The Year Two data, which are presented in Figure 2, show a distribution of auroral nitric oxide that is nearly identical to the results in Figure 1. The maximum density also occurs between geomagnetic longitudes $60^{\circ} \mathrm{W}$ and $90^{\circ} \mathrm{W}$. The smallest densities occur between longitudes $60^{\circ} \mathrm{E}$ and $90^{\circ} \mathrm{E}$. This comparison suggests that the distribution of auroral nitric oxide shown in Figures 1 and 2 is typical. This further suggests that the asymmetric distribution of precipitating electron flux that is inferred from the nitric oxide distribution is controlled by some intrinsic property of the magnetic field.

\section{Model Calculations}

The density of nitric oxide in the auroral region may be correlated to the flux of precipitating electrons with the aid of a thermospheric model [Barth, 1992]. Auroral primary electrons with a characteristic energy of $4 \mathrm{keV}$ penetrate to the $100-110 \mathrm{~km}$ level of the thermosphere. These $4 \mathrm{keV}$ electrons ionize the major constituents, $\mathrm{N}_{2}, \mathrm{O}$, and $\mathrm{O}_{2}$ and produce nitric oxide. The loss process for nitric oxide is the photodissociation of nitric oxide by ultraviolet solar radiation which has a time constant of 1.6 days. Because the atomic nitrogen produced in the photodissociation of nitric oxide also destroys nitric oxide, the effective time constant for the loss of nitric oxide is 0.8 days (19 hours).

A time-dependent calculation of the production and loss of nitric oxide during an auroral electron precipitation event was performed for the conditions present in the auroral region at a latitude of $65^{\circ} \mathrm{N}$ geomagnetic latitude. The time chosen for this model calculation was the time of the equinox when there are equal periods of solar illumination and darkness. The auroral electron flux was turned on for a 6 hour period of darkness in the evening starting at 6:00 PM. At midnight, the auroral flux was turned off. The results are shown in Figure 3 for three values of the auroral electron flux starting at midnight just after the electron flux is turned off. During the period of darkness following the end of the electron precipitation, the nitric oxide density remains almost constant. When the atmosphere is illuminated starting at dawn, the nitric oxide density decreases. In the four and a half hour period between dawn and 10:30 AM, the nitric oxide density decreases by $20 \%$ for all values of energy flux. These calculations illustrate how the measurement of nitric oxide at a local time of 10:30 AM may be related to the production of nitric oxide in darkness twelve hours earlier. The amount of nitric oxide produced during the electron precipitation is proportional to the flux of precipitating electrons and the length of time of the precipitation event.

\section{Geomagnetic Activity}

To further explore the role of precipitating electrons in the production of nitric oxide, the distribution of nitric oxide in the polar region for varying levels of geomagnetic activity was investigated. The equinox periods between March 20, 1998 and March 20, 1999 (equinox \pm 45 days) were chosen for this investigation to allow the use of the results of the model calculation in Figure 3. Nitric oxide densities for those days when the Ap index was greater than 12 were summed and are displayed in Figure 4. The color scale for Figure 4 is set $70 \%$ higher than the color scale for Figure 1 so that both figures may use the full range of the color scale. During this 183 day period, there were 70 days of geomagnetic activity greater than 12. The nitric oxide density in Figure 4 was processed the same way as in Figure 1. This image shows that the precipitating electrons create the largest amount of nitric oxide in the auroral oval between $60^{\circ}$ and $70^{\circ} \mathrm{N}$ geomagnetic latitude. However, there is again an asymmetry in the longitudinal distribution of nitric oxide. In the latitude band between $60^{\circ}$ and $70^{\circ} \mathrm{N}$ geomagnetic latitude, the largest amount of nitric oxide is at a geomagnetic longitude of $90^{\circ} \mathrm{W}$ and the smallest amount at $90^{\circ} \mathrm{E}$ as in Figures 1 and 2.

The calculations shown in Figure 3 were used to develop an algorithm to convert nitric oxide density into the flux of precipitating electrons that is capable of producing the observed density. This algorithm was applied to the equinox observations at high geomagnetic activity (Figure 4). At $65^{\circ}$ $\mathrm{N}, 90^{\circ} \mathrm{W}$, the maximum flux is $1.27 \mathrm{~mW} / \mathrm{m}^{2}$ and at $65^{\circ} \mathrm{N}$, $90^{\circ} \mathrm{E}$ the latitudinal maximum is $0.57 \mathrm{~mW} / \mathrm{m}^{2}$. The ratio of the maximum to the minimum flux in the auroral oval is 1.75. This means that during the 70 days of high auroral activity $(\mathrm{Ap}>12)$ during the 1998-9 equinox periods the electron flux precipitating into the auroral oval was $75 \%$ greater at $90^{\circ} \mathrm{W}$ than at $90^{\circ} \mathrm{E}$.

\section{Magnetic field control of electron precipitation}

As discussed in the Introduction, auroral luminosity is clearly associated with strong electron precipitation: Both of these physically related phenomena tend to maximize in the premidnight local time sector and are associated with magnetospheric substorms and enhanced geomagnetic activity [see Baker et al., 1996 for a review of substorm models]. In this paper we have made the further association of nitric oxide production in the lower thermosphere with auroral electron precipitation. If local time were the only controlling factor in NO production, we would expect to see a rather uniform distribution of $\mathrm{NO}$ around the Earth in geomagnetic longitude. However, when SNOE data are averaged over seasonal and annual time scales, we find a clear geomagnetic, rather than local time, asymmetry in NO production. This suggests that asymmetries in the Earths magnetic field, and 
its extension to the high-latitude atmosphere and magnetosphere, play a clearly discernible role in long-term electron precipitation and resultant NO production.

An obvious candidate for such control is the offset, tilted dipole magnetic field of the Earth [e.g., Roederer, 1970]. The Earths field may be well approximated by a magnetic dipole that is tilted by $11^{\circ}$ and offset by $\sim 500 \mathrm{~km}$ from the center of the Earth [e.g., Olsen et al., 2000]. The tilt of the dipole is well accounted for in the CGM coordinate system discussed in the Observations section of this paper. The offset of the dipole leads to a weaker magnetic field at low altitudes in the south Atlantic region. Electrons mirroring at large mirror field strengths and drifting (eastward) into the south Atlantic region from the west see a weak magnetic field (Roederer, 1970). Such particles move further down toward the Earth in order to reach their appropriate mirror magnetic field strength. However, in doing so these electrons enter into the denser atmosphere and are absorbed into the lower thermosphere. This "windshield wiper effect" depletes the electrons throughout the anomaly region. On the east side of the weak magnetic field region, where a higher magnetic field strength again occurs, the electrons can again be replenished by pitch angle scattering of near-equatorial electrons that are produced by substorm and other acceleration effects. We suggest, therefore, that in the present SNOE northern hemisphere observations of NO, we are seeing "normal" electron precipitation west of the weak magnetic field region, but much weakened precipitation of electrons in the weak magnetic field region and eastward of it. Of course, in any particular active interval, local time effects and auroral substorm processes will dominate the auroral luminosity, electron precipitation, and NO production. However, over the long term, averaging over many event intervals, the magnetic field asymmetry signal in the NO density will emerge clearly.

\section{Summary}

Nitric oxide that is produced in the auroral region by precipitating keV electrons may be used to deduce the flux of auroral electrons. The observed nitric oxide density is a measure of the amount of precipitation that has occurred during the previous 19 hours. Satellite observations of the northern auroral region show the largest density of nitric oxide in a band between $60^{\circ}$ and $70^{\circ} \mathrm{N}$ geomagnetic latitude centered on the north magnetic pole. However, the density of nitric oxide around the auroral zone is not uniform with the densities at western geomagnetic longitudes being greater than those at eastern longitudes. Satellite observations for two successive one-year periods show a similar distribution of nitric oxide suggesting that the 1998 and 1999 observations are typical and that there is a true, persistent asymmetry in the longitudinal distribution of nitric oxide. Satellite observations of nitric oxide during periods of high geomagnetic activity show an even larger west-east asymmetry in the distribution of nitric oxide around the auroral oval. Using an algorithm derived from a model calculation, the calculated flux of precipitating electrons at $90^{\circ} \mathrm{W}$ geomagnetic longitude is $75 \%$ larger than the electron flux at $90^{\circ} \mathrm{E}$.

We suggest that the longitudinal asymmetry in the flux of precipitating electrons is caused by the longitudinal variation of the magnetic field strength around the auroral oval. The electron flux is depleted east of the longitude where the magnetic field strength is weaker.

Acknowledgments. The Student Nitric Oxide Explorer (SNOE) mission has been managed for the National Aeronautics and Space Administration by the Universities Space Research Association.

\section{References}

Akasofu, S.-I., Physics of Magnetospheric Substorms, D. Reidel, Hingham, MA, 1977.

Bailey, S.M., et al., Measurements of the solar soft x-ray irradiance from the Student Nitric Oxide Explorer, Geophys. Res. Lett., 26, 1255-1258, 1999.

Baker, D. N., et al., The neutral line model of substorms: Past results and present view, J. Geophys. Res., 101, 12995, 1996.

Barth, C. A., Nitric oxide in the Lower Thermosphere, Planet. Space Sci., 40, 315-336, 1992.

Barth, C. A., S. M. Bailey, and S. C. Solomon, Solar-terrestrial coupling: Solar soft x-rays and thermospheric nitric oxide, Geophys. Res. Letters, 26, 1251-1254, 1999.

Feldstein, Y. I. and Yu. I. Galperin, The Auroral Luminosity Structure in the High-Latitude Upper Atmosphere: Its Dynamics and Relationship to the Large-Scale Structure of the Earths Magnetosphere, Rev. Geophys., 23, 217, 1985.

Liou, K., P. T. Newell, and C.-I. Meng, Synoptic auroral distribution: A survey using Polar ultraviolet imagery, J. Geophys. Res., 102, 27,197, 1997.

Newell, P. T., K. M. Lyons, and C.-I. Meng, A large survey of electron acceleration events, J. Geophys. Res., 101, 2599, 1996.

Olsen, N., et al., Orsted Initial Field Model, Geophys. Res. Lett., 27, 3607-3610, 2000.

Roederer, J.G., Dynamics of Geomagnetically Trapped Radiation, Springer-Verlag, New York, 1970.

C.A. Barth, D.N. Baker, and K.D. Mankoff Laboratory for Atmospheric and Space Physics, University of Colorado, Boulder, CO 80309-0590. (e-mail: charles.barth@lasp.colorado.edu)

S.M. Bailey, Center for Atmospheric Sciences, Hampton University, 23 Tyler Street, Hampton, VA 23668. (e-mail: scott.bailey@hamptonu.edu)

(Received November 16, 2000; accepted January 24, 2001.) 